\title{
Bronchial carcinoma in an ovarian cystic teratoma (dermoid)
}

\author{
H. FOX \\ From the Departments of Pathology and Obstetrics, University of Manchester
}

SYNOPSIS An ovarian cystic teratoma (dermoid) in which a squamous cell carcinoma had developed from bronchial epithelium via a process of basal cell hyperplasia, squamous metaplasia, and malignant change in situ is described. It is suggested that this sequence of changes may be due to the carcinogenic action of a constituent of the cyst contents.

Malignant change in an ovarian cystic teratoma (dermoid) is uncommon but not rare. In an exhaustive survey of the literature Peterson (1957) was able to collect 147 fully authenticated cases and further cases have been reported since that date (Kelley and Scully, 1961). Of the reported malignant tumours $88 \%$ have been squamous cell carcinomata (Peterson, 1957), though many other tumour types have also been recorded, e.g., malignant melanoma (MarcialRojas and Ramírez de Arellano, 1956), thyroid adenocarcinoma (Mayberger, 1959), carcinoid tumour (Stewart, Willis, and de Saram, 1939; Blackwell and Dockerty, 1946; Betson and Golden, 1959), and leiomyosarcoma (Kelley and Scully, 1961).

When a squamous cell carcinoma develops in a previously benign cystic teratoma it is usually assumed to have arisen from epidermal elements in the tumour, and development of such a tumour from non-epidermal elements has not been recorded. It is the purpose of this paper to record a squamous cell carcinoma arising from bronchial epithelium in an ovarian cystic teratoma via a process of metaplasia and malignant change. This tumour is further noteworthy in so far as it showed extensive areas of carcinoma in situ.

\section{CASE REPORT}

A widow aged 62 was admitted to St. Mary's Hospital, Manchester, complaining of right-sided lower abdominal pain that had been present for five weeks. The pain was intermittent and associated with vomiting. There had been no vaginal bleeding. On examination a cystic pelvic mass was palpable. At laparotomy this was found to be a tumour of the right ovary that had undergone torsion. The left ovary and the Fallopian tubes appeared normal. The uterus was small, mobile, and healthy. A bilateral oophorectomy was performed.

Received for publication 22 June 1964.

\section{PATHOLOGICAL EXAMINATION}

The left ovary was slightly enlarged and on section contained a multilocular cystic tumour $1.5 \mathrm{~cm}$. in diameter. The right ovary was replaced by a cystic tumour measuring $15 \times 12 \times 6 \mathrm{~cm}$. On section the cyst was bilocular and contained pultaceous yellow material in which were embedded numerous hairs.

On microscopy, the small cyst in the left ovary was a multilocular dermoid cyst lined by squamous epithelium in which were hair follicles and sebaceous glands. No other tissue was present in the tumour and there was no evidence of malignancy.

The right ovarian tumour was also a dermoid, and the cyst wall was lined partially by squamous epithelium in which sebaceous glands and hair follicles were present, and partially by ciliated columnar epithelium. The ciliated epithelium was of the type normally seen in the lower respiratory tract, i.e., in the bronchi. In the stroma of the cyst wall were many sieve-like microcytic areas together with giant cells. The squamous epithelium of epidermal type lining the cyst was, in all areas, regular without any evidence of malignant change. The respiratory type epithelium, however, showed a pattern of graded change ranging from basal cell hyperplasia to invasive squamous cell carcinoma. There was direct continuity between an area of normal respiratory epithelium and one showing basal cell hyperplasia (Fig. 1), blending gradually into an area of squamous metaplasia in which the cells showed sufficient nuclear and cytoplasmic irregularity for this to be considered a squamous carcinoma in situ (Fig. 2). This in-situ carcinomatous change involved a considerable area of the cyst wall. There was, however, in two separate and discrete areas, invasion of the underlying stroma by malignant squamous cells (Fig. 3). The cellular invasion did not extend 


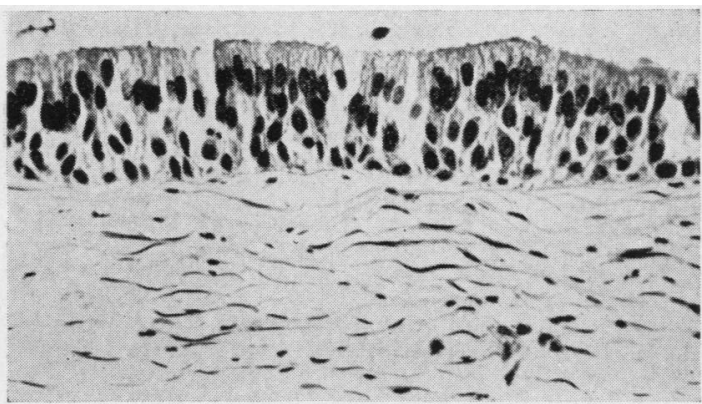

FIG. 1. Respiratory type epithelium lining the cyst. There is some degree of basal cell hyperplasia.

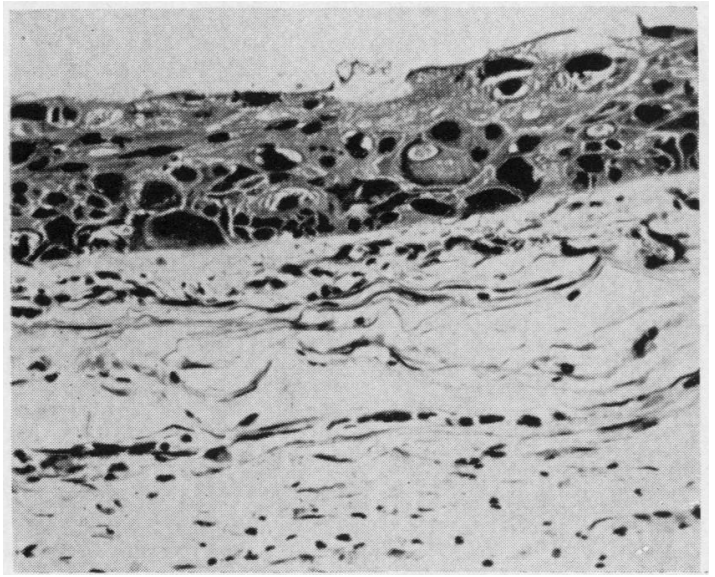

FIG. 2. Area of squamous metaplasia. There is marked nuclear and cytoplasmic pleomorphis, and the appearances are those of a carcinoma in situ.

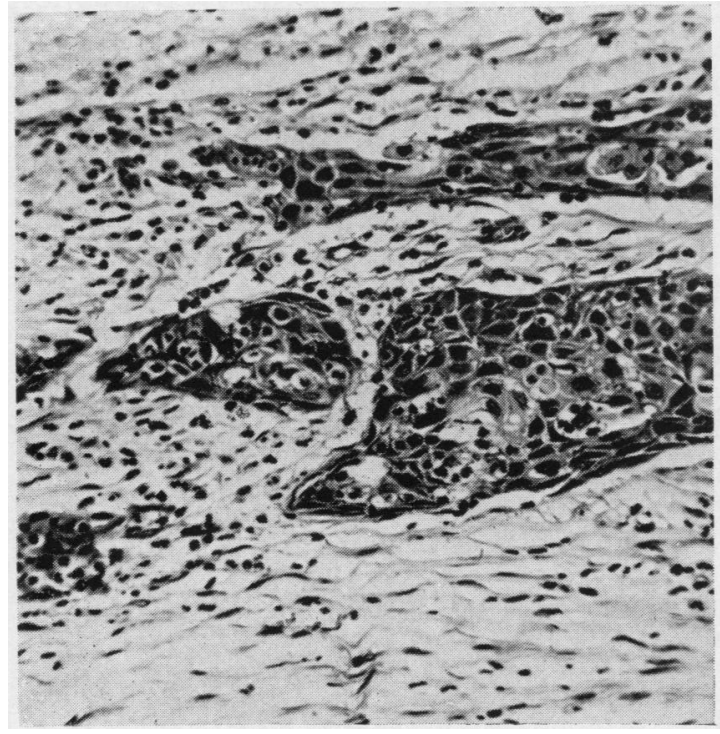

FIG. 3. Invasion of stroma of cyst wall by clumps of malignant squamous cells. through to the external surface of the cyst. The malignant squamous epithelium was in direct continuity only with respiratory epithelium and there was at no point any continuity between the squamous carcinoma and the normal epidermal-type squamous epithelium.

\section{DISCUSSION}

There seems little doubt that the tumour described above is a squamous cell carcinoma arising from bronchial type respiratory epithelium in an ovarian cystic teratoma (dermoid). This appears to be the first such tumour recorded, and noteworthy further for the extensive areas of carcinoma in situ. Areas of in-situ carcinoma in an ovarian dermoid have been noted in two previous cases (Peterson, Prevost, Edmunds, Hundley, and Morris, 1955). The principal interest of this case, however, is that the bronchial epithelium in the teratoma shows exactly the sequence of changes that is thought to occur in the epithelium of the bronchial tree of heavy cigarette smokers (Auerbach, Gere, Forman, Petrick, Smolin, Muehsam, Kassouny, and Stout, 1957). This sequence of changes is basal cell hyperplasia progressing to squamous metaplasia, and then on to squamous carcinoma. It appears possible, therefore, that this pattern of change represents the characteristic response of bronchial epithelium to exposure to a carcinogenic agent. If this is accepted, then it would appear that the tumour epithelium would possibly also have been subjected to the action of a carcinogenic agent. If this is so, then the carcinogenic agent must be a constituent of the cyst contents. It is of interest that cholesterol is contained in many ovarian cystic teratomata and that pure cholesterol has been proved experimentally to be a carcinogenic agent (Hieger, 1959, 1962). This possibility of a carcinogen in the contents of an ovarian dermoid has previously been suggested by Willis (1937), who was able to retrieve some of the contents of an ovarian dermoid showing malignant change and after drving and evaporation, applied this substance to the skin of 12 mice for a period of four months. He was not able to produce a skin carcinoma by this method, but as he later pointed out (Willis, 1960), this experiment was chemically and physically a very crude one, and it is possible that more sophisticated and complete investigations may produce a more rewarding result.

It can be argued that the incidence of malignant change in ovarian dermoids is low $(1.8 \%)$ if there is truly a carcinogenic agent in the content of these cysts. It must be remembered, however, that a very long period of exposure is required for the production of a malignant tumour (probably 30-40 
years in the bronchial tree) and that the majority of ovarian dermoids are removed because of pain or abdominal discomfort, possibly before sufficient time has elapsed for a carcinoma to develop.

I should like to thank Dr. F. A. Langley for his advice and criticism; Professor W. I. C. Morris, in whose department this paper was prepared, and Mr. B. W. Figg for the photomicrographs.

\section{REFERENCES}

Auerbach, O., Gere, J. B., Forman, J. B., Petrick, T. G., Smolin, H. J., Muehsam, G. E., Kassouny, D. Y., and Stout, A. P. (1957). New Engl. J. Med., 256, 97.
Betson, J. R. Jr., and Golden, M. L. (1959). Amer. J. Obstet. Gynec., $77,1345$.

Blackwell, W. J., and Dockerty, M. B. (1946). Ibid., 51, 575.

Hieger, I. (1959). Brit. J. Cancer, 13, 439.

(1962). Ibid., 16, 716.

Kelley, R. R., and Scully, R. E. (1961). Cancer (Philad.), 14, 989.

Mayberger, H. W. (1959). Amer. J. Obstet. Gynec., 78, 817.

Marcial-Rojas, R. A., and Ramírez de Arellano, G. A. (1956). Cancer (Philad.), 9, 523.

Peterson, W. F., Prevost, E. C., Edmunds, F. T., Hundley, J. M. Jr., and Morris, F. K. (1955). Amer. J. Obstet. Gynec., 70, 368.

(1957). Obstet. Gynec. Surv., 12, 793.

Stewart, M. J., Willis, R. A., and de Saram, G. S. W. (1939). J. Path Bact., 49, 707.

Willis, R. A. (1937). Ibid., 45, 49.

(1960). In The Pathology of Tumours, 3rd ed. p. 974, Butterworths, London. 